\title{
Equitable COVID-19 vaccine prioritization: front-line workers or 65-74 year olds?
}

Eva Rumpler MS ${ }^{*}$, Justin M. Feldman ScD², Mary T. Bassett MD², Marc Lipsitch DPhil ${ }^{1}$

${ }^{1}$ Center for Communicable Disease Dynamics, Department of Epidemiology, Harvard T.H. Chan School of Public Health, 677 Huntington Ave, Boston, MA 02115, USA.

2 Harvard FXB Center for Health and Human Rights, 651 Huntington Ave, Boston, MA 02115, USA.

* Corresponding author, email: erumpler@hsph.harvard.edu

\section{Abstract}

Background:

The COVID-19 epidemic in the United States has been characterized by two stark disparities. COVID-19 burden has been unequally distributed among racial and ethnic groups and at the same time the mortality rates have been sharply higher among older age groups.

These disparities have led some to suggest that higher equity could be attained by vaccinating front-line workers before vaccinating older individuals, who in the US are disproportionately Non-Hispanic White.

Methods:

We compare the performance of two distribution policies, one allocating vaccines to frontline workers and another to older individuals aged 65-74-year-old. We estimate both the number of lives saved and the number of years of life saved under each of the policies, overall and in every race/ethnicity groups, in the United States and every state.

Findings:

We show that prioritizing COVID-19 vaccines for 65-74-year-olds saves both more lives and more years of life than attributing vaccines front-line workers in each racial/ethnic group, in the United States as a whole and in nearly every state.

Interpretation:

When evaluating equity in vaccine allocation policies, the overall benefit to impact of each population subgroup should be considered, not only the proportion of doses that is distributed to each subgroup. Further work can identify prioritization schemes that perform better on multiple equity metrics.

Funding:

The funding sources played no role in this research. 
medRxiv preprint doi: https://doi.org/10.1101/2022.02.03.22270414; this version posted February 4, 2022. The copyright holder for this preprint (which was not certified by peer review) is the author/funder, who has granted medRxiv a license to display the preprint in perpetuity.

It is made available under a CC-BY-NC-ND 4.0 International license .

\section{Introduction}

Two stark disparities define the mortality impact of the COVID-19 epidemic in the United States. The risk of death given infection (infection fatality rate) rises sharply with age. By one estimate, this increase is exponential, about 10-fold for each 19-year increase in age 1. Another estimate fits a linear increase and finds a 1.18 percentage-point absolute increase in infection fatality rate per decade of age ${ }^{2}$. At the same time, Black, Hispanic, and Native American persons in the US have experienced confirmed infections, hospitalizations, and deaths at dramatically higher rates than White or Asian persons ${ }^{3}$, reflecting a pattern of racial/ethnic and socioeconomic disparity that is observed also in other populations ${ }^{4-7}$. As of March 2021, White and Asian individuals in the US have similar age-adjusted COVID-19 mortality rates (respectively 121/100,000 and 117/100,000). Compared to White individuals, the age-adjusted COVID-19 mortality rate is 1-7-fold higher among Black individuals (241/100,000), 1.9-fold higher among Indigenous individuals $(263 / 100,000)$, $2 \cdot 0$-fold higher among Hispanic individuals $(287 / 100,000)$ and $2 \cdot 2$-fold higher among Pacific Islander individuals $(312 / 100,000)^{8}$. An additional relevant fact that connects these two disparities is that White and Asian populations are older on average than Black, Hispanic, and other racial/ethnic groups in the United States.

These two disparities and their interaction have received attention in discussions over vaccine prioritization. While prioritization of older adults and individuals with comorbid conditions predisposing them to higher infection-fatality rates is under most scenarios expected to save more lives in the aggregate than non-prioritized strategies ${ }^{9-12}$, such a strategy in the US involves providing more vaccine doses, earlier, to White individuals and fewer to Black, Hispanic, Asian and Native American people, due to the differences in age distribution. An alternative strategy, that of prioritizing essential or front-line workers, has been discussed as a way to provide more vaccine doses to those racial/ethnic groups that are hardest hit by COVID-19, because essential workers are younger and disproportionately include members of these groups.

Here we quantify the potential impacts overall and by race/ethnicity, comparing two groups that have been widely discussed for prioritization below long-term care residents and health care workers and those 75 and older, but above other members of the population: i) individuals 65-74 not in long-term care or nursing homes, and ii) front-line (non health care) workers. For the United States and each state individually, we quantify the extent to which these two policies would provide vaccines to members of different racial and ethnic groups, and we ask the further question of how the two policies compare in terms of expected lives and years of life saved overall and for each racial/ethnic group.

Such estimates require certain modeling assumptions. We outline those in detail in Methods, but we emphasize here the most important. First, we consider only the direct effects of vaccination in preventing death from COVID-19 in vaccinated persons. Indirect effects on transmission are not considered in this study, to simplify and make transparent the analysis and because vaccines' effects on transmission were not clear at the time of vaccine allocation decisions. Second, we make the assumption that from the moment the prioritization decision is made, future COVID-19 deaths in strata defined by age group, race/ethnicity and state, and occupation (essential worker or not) are proportional to those 
medRxiv preprint doi: https://doi.org/10.1101/2022.02.03.22270414; this version posted February 4, 2022. The copyright holder for this preprint (which was not certified by peer review) is the author/funder, who has granted medRxiv a license to display the preprint in perpetuity.

It is made available under a CC-BY-NC-ND 4.0 International license .

estimated for the period prior to January 30, 2021. This assumption links future disparities in death rates related to all these factors to past ones. Third, we assume that vaccine uptake and effectiveness is even across race/ethnic groups within an age group and state under each policy; we discuss the impact of this assumption later. The second and third assumptions together enable a comparison of the projected number of lives saved in each race/ethnicity, by state, by allocating a fixed number of vaccine doses under each of the two policies.

\section{Methods}

\subsection{Notations}

We repeat our analyses across multiple age categories, race/ethnicity groups and US states. We consider various geographical entities $k$ : either the entirety of the United States, or any one of 50 states or the District of Columbia. The age groups considered are either 65-74 year old for policy $S$, or 16-64 (further detailed into16-24, 25-34, 35-44, 45-54, 55-64) for front-line workers for policy $F$. We conducted our analyses for seven race/ethnicity categories (Non-Hispanic Whites, Hispanics, Non-Hispanic Blacks or African American, Non-Hispanic Asians, Non-Hispanic Two or more races, Non-Hispanic American Indian or Alaska Native, Non-Hispanic Native Hawaiian or other Pacific Islander).

Notations used are detailed in Table 1 below.

Table 1: Notation and input values

\begin{tabular}{|c|c|c|c|}
\hline Notation & Meaning & Values & Source \\
\hline$v$ & $\begin{array}{l}\text { Number of vaccine courses available for } \\
\text { individuals of a given age } i \text { a given state } \\
k\end{array}$ & 1,000 (arbitrary) & \\
\hline$R$ & $\begin{array}{l}\text { Increased risk of COVID-19 deaths for } \\
\text { front-line workers }\end{array}$ & $1 \cdot 56$ & 13 \\
\hline$D_{i j k}$ & $\begin{array}{l}\text { COVID-19 deaths among individuals of } \\
\text { a given age } i \text { and race/ethnicity } j \text { in } \\
\text { state } k \text { that take place outside nursing } \\
\text { homes and long-term care facilities }\end{array}$ & $\begin{array}{l}20 \% \text { of the number of COVID- } \\
19 \text { deaths among these } \\
\text { individuals between January } \\
1 \text { st } 2020 \text { and January } 31 \text { st } \\
2021\end{array}$ & 14,15 \\
\hline$D_{i j k}^{F}$ & $\begin{array}{l}\text { COVID-19 deaths among front-line } \\
\text { workers of a given age } i \text { and } \\
\text { race/ethnicity } j \text { in state } k \text { that take } \\
\text { place outside nursing homes and long- } \\
\text { term care facilities }\end{array}$ & & 14,15 \\
\hline$N_{i j k}$ & $\begin{array}{l}\text { Number of individuals of a given age } i \\
\text { and race/ethnicity } j \text { in state } k\end{array}$ & & 16 \\
\hline
\end{tabular}




\begin{tabular}{|c|c|c|}
\hline Notation & Meaning & Source \\
\hline$N_{i k}$ & $\begin{array}{l}\text { Number of individuals of a given age } i \\
\text { of any race/ethnicity in state } k\end{array}$ & 16 \\
\hline$N_{i j k}^{F}$ & $\begin{array}{l}\text { Number of front-line workers of a given } \\
\text { age } i \text { and race/ethnicity } j \text { in state } k\end{array}$ & 16 \\
\hline$N_{k}^{F}$ & $\begin{array}{l}\text { Number of front-line workers of any } \\
\text { age and any race/ethnicity in state } k\end{array}$ & 16 \\
\hline$L S_{j k}$ & $\begin{array}{l}\text { Number of lives in each race/ethnicity } \\
\text { group } j \text { saved by vaccinating } v 65-74 \\
\text { year old in state } k\end{array}$ & \\
\hline$L F_{j k}$ & $\begin{array}{l}\text { Number of lives in each race/ethnicity } \\
\text { group } j \text { saved by vaccinating } v \text { front- } \\
\text { line workers in state } k\end{array}$ & \\
\hline ratio $_{j k}$ & $\begin{array}{l}\text { Ratio of } L S_{j k} \text { and } L F_{j k} \text { comparing the } \\
\text { efficacy of both policies in a given } \\
\text { race/ethnicity } j \text { and a state } k \text { in terms } \\
\text { of number of lives saved }\end{array}$ & \\
\hline$Y S_{j k}$ & $\begin{array}{l}\text { Number of years of life in each } \\
\text { race/ethnicity group } j \text { saved by } \\
\text { vaccinating } v 65-74 \text { year old in state } k\end{array}$ & \\
\hline$Y F_{j k}$ & $\begin{array}{l}\text { Number of years of life in each } \\
\text { race/ethnicity group } j \text { saved by } \\
\text { vaccinating } v \text { front-line workers in } \\
\text { state } k\end{array}$ & \\
\hline $\operatorname{ratio}_{j k}$ & $\begin{array}{l}\text { Ratio of } Y S_{j k} \text { and } Y F_{j k} \text { comparing the } \\
\text { efficacy of both policies in a given } \\
\text { race/ethnicity } j \text { and a state } k \text { in terms } \\
\text { of number of years of life saved }\end{array}$ & \\
\hline
\end{tabular}

\subsection{Data sources and estimation}

\subsubsection{Estimating the number of COVID-19 deaths outside of nursing homes and long term care facilities by state, race/ethnicity and age categories.}

We obtained the number of COVID-19 deaths by state, age, race and Hispanic origin group reported to the National Center for Health Statistics (NCHS) between January 1st 2020 and January 30th $2021^{14}$. We also extracted the proportion of COVID-19 deaths that took place outside of nursing homes and long term care facilities between January 4th 2020 and January 30 th 2021 , by state and age categories from the NCHS ${ }^{15}$. Deaths counts ranging between 1 and 9, which were not reported due to the NCHS confidentiality standards, were approximated by the median value 5 . 
medRxiv preprint doi: https://doi.org/10.1101/2022.02.03.22270414; this version posted February 4, 2022. The copyright holder for this preprint (which was not certified by peer review) is the author/funder, who has granted medRxiv a license to display the preprint in perpetuity.

It is made available under a CC-BY-NC-ND 4.0 International license .

As nursing home and long-term care facilities residents and employees have access to vaccination before 65-74 and front-line workers, we do not consider deaths that took place in those settings as part of our analysis. Assuming that this proportion of COVID-19 deaths in nursing homes and long term care facilities is constant across races and ethnicity for a given state and age category, we compute the proportion of COVID-19 deaths that took place outside of these settings for each joint stratum of state, age category and race.

\subsubsection{Extracting the number of front-line workers and total number of individuals by state, race and age categories}

We obtained the number of individuals in each US state, race and age category from the American Community Survey (ACS) estimates for the year 2019 16. The demographic variables we included were State, Age, Occupation, Race and Hispanic origin. We categorized these into seven race/ethnicity groups: Non-Hispanic Whites, Hispanics, NonHispanic Blacks or African American, Non-Hispanic Asians, Non-Hispanic Two or more races, Non-Hispanic American Indian or Alaska Native, Non-Hispanic Native Hawaiian or other Pacific Islander.

For each state, race/ethnicity, and 10-year age category 16-64, we also construct the number of front-line workers employed in occupation categories corresponding to the definition of workers who are likely to be exposed to COVID-19 as defined by the state of Massachusetts ${ }^{17}$. This list includes K-12 educators, drivers, retail, funeral, food and beverage workers. Summary tables showing the occupations included, as well as the share of individuals from each race/ethnicity in each occupation can be found in Supplementary Table 1.

\subsubsection{Estimating the mortality rate among front-line workers}

Because of higher exposure to infection and possibly other factors, front-line workers may experience a higher risk of COVID-19 death than other individuals of the same age, race/ethnicity, and state. To estimate the increased mortality rate among front-line workers, we multiply the mortality rate of a given age/state/race category by $R$, the increased risk due to their increased exposure to SARS-CoV-2 at work and possible increased mortality from other factors.

$$
\frac{D_{i j k}^{F}}{N_{i j k}^{F}}=R * \frac{D_{i j k}}{N_{i j k}}
$$

where:

$\frac{D_{i j k}^{F}}{N_{i j k}^{F}}$ is the mortality rate among front-line workers of a given age group $i$, race/ethnicity group $j$ and state $k$, and

$\frac{D_{i j k}}{N_{i j k}}$ is the mortality rate among adults regardless of their occupation of that same age $i$, race/ethnicity $j$ and state $k$.

Mutambudzi et al. ${ }^{13}$ provide risk ratios for severe COVID-19 by occupational group. When 
medRxiv preprint doi: https://doi.org/10.1101/2022.02.03.22270414; this version posted February 4, 2022. The copyright holder for this preprint (which was not certified by peer review) is the author/funder, who has granted medRxiv a license to display the preprint in perpetuity.

It is made available under a CC-BY-NC-ND 4.0 International license .

compared to non-essential workers, education workers, food workers and transport workers appear to have risk ratios of respectively $1.56(0 \cdot 87-2 \cdot 91), 0 \cdot 84(0 \cdot 39-1 \cdot 80)$ and $1.43(0 \cdot 78-2 \cdot 63)$ in a fully adjusted model. We use 1.56 as an estimate of $R$ in the rest of our analysis.

\subsection{Estimation of the number of lives saved by a fixed number of vaccine courses $v$ in a given state $k$}

We aim at estimating a quantity proportional to the number of lives saved among race/ethnicity groups $j$ by allocating a fixed number of vaccine courses $v$ to individuals of a given age group $i$ in a given US state $k$. We first describe the estimation for the purely agebased policy $S$ and then describe the approach for occupation-based policy $F$.

Throughout our analysis, we assume $v=1,000$ for each state, and 95\% vaccine efficacy. Because all calculations are linear in $v$ and in efficacy against death, the comparative results are unaffected by the choice of values for these variables. As noted above we make the further assumption that future COVID-19 deaths in an (age, state, race) group in the absence of vaccine would be proportional to the number of deaths up to January $31,2021$. To present results, we assume that the future number of deaths in the absence of vaccine is $20 \%$ as large as the number to January 31,2021 , but again this choice has no effect on the relative magnitudes of benefit from different policies.

\subsubsection{Estimating the number of lives saved under policy $S$}

As this policy allocated vaccines purely by age category, the number of doses allocated to each race/ethnicity group $j$ is proportional to the probability that individuals in age category $i$ and state $k$ belong to each race/ethnicity group $j$.

Under these assumptions, the number of lives saved in a given age group $i$ and race/ethnicity group $j$ by $v$ vaccination in state $k$ is proportional to:

$$
v * \frac{D_{i j k}}{N_{i j k}} * \frac{N_{i j k}}{N_{i k}}
$$

where :

$v$ is the number of vaccine courses available for individuals of a given age $i$ in a given state $k$,

$\frac{D_{i j k}}{N_{i j k}}$ is the mortality rate among individuals of age $i$, race/ethnicity $j$ in state $k$, and

$\frac{N_{i j k}}{N_{i k}}$ is the probability that a vaccine goes to a $j$ member of the age group $i$ in state $k$, assumed to be the share of $j$ individuals in the age group $i$.

We can then drop the $N_{i j k}$ term in equation 2 and write that the number of lives saved is proportional to 


$$
v * \frac{D_{i j k}}{N_{i k}}
$$

We apply this equation to estimate the number of lives saved by allocating a fixed number of vaccine courses $v$ to one of two groups in a given state $k$ : older individuals aged 65-74 years not in long-term care or nursing homes (policy $S$ ) or public-facing front-line workers aged 16-64 (policy $F$ ).

We're first interested in estimating the number of lives in each race/ethnicity group $j$ saved by vaccinating $v$ 65-74 year old, termed $L S_{j k}$. Applying the equations defined above in the age category 65-74 year old, we obtain:

$$
L S_{j k}=v * \frac{D_{65-74 j k}}{N_{65-74 k}}
$$

\subsubsection{Estimating the number of lives saved under policy $F$}

Next, we estimate the number of lives saved among each race/ethnicity $j$ by vaccinating $v$ front-line workers, termed $L F_{j k}$.

Two layers of complexity need to be taken into account when estimating $L F_{j k}$. First, as detailed above, deaths counts for front-line workers are not available and mortality rates among front-line workers need to be estimated from mortality rates in the general population. Second, we need to account for front-line workers having a different age distribution than the general population of adults aged 16 to 64 year old, as shown in Supplementary Figure 2 . We thus start by computing $L F_{i j k}$ among each of five age categories $i$ : 16-24, 25-34, 35-44, 45-54, and 55-64 year olds.

Similarly as above,

$$
L F_{i j k}=v * R * \frac{D_{i j k}}{N_{i j k}} * \frac{N_{i j k}^{F}}{N_{k}^{F}}
$$

where :

$R * \frac{D_{i j k}}{N_{i j k}}$ is the mortality rate among front-line workers, as detailed in section 4.2 .3 above, and

$\frac{N_{i j k}^{F}}{N_{k}^{F}}$ is the probability that a vaccine goes to a front-line worker of race/ethnicity $j$ member of the age group $i$ in state $k$, assumed to be the share of front-line workers of that age/race/ethnicity $i j$ in state $k$. 
We then sum all $L F_{i j k}$ over the five age categories $i$ among front-line workers to obtain the total number of lives saved for front-line workers aged 16 to 64 years, $L F_{j k}$.

$$
L F_{j k}=\sum^{i} L F_{i j k}
$$

\subsubsection{Comparing policy $S$ and policy $F$}

For each race/ethnicity $j$ and state $k$ of interest, we compute the ratio $L_{j k}$ of the number of lives saved under each policy $S$ and $F$ for a given number of vaccine doses $v$. A ratio $L_{j k}$ larger than 1 indicates that policy $S$ is preferable to policy $F$ for race/ethnicity $j$ in state $k$.

$$
\operatorname{ratioL}_{j k}=\frac{L S_{j k}}{L F_{j k}}
$$

\subsection{Estimation of the number of years of life saved by a fixed number of vaccine courses $v$ in a given state $k$}

Next, we extend our analysis by estimating the number of years of life saved, instead of the number of lives.

We extend the calculations above to include an estimate of the expected number of life years saved among race/ethnicity groups. We extracted the expectations of life at different age categories between 15 and 74 years old from the WHO Global Health Observatory (GHO) ${ }^{18}$. As estimates are given for 5-year age bins in the WHO GHO, we average estimates two by two to obtain estimated for our 10-year age bins of interest, as shown in Supplementary Table 2 .

We then adapt the calculations of the absolute number of years of life lost (YLL) described by Martinez et al. ${ }^{19}$ to the estimation of number of years of life saved (YLS):

$$
Y_{i j k}=D_{i j k} * S L E_{i}
$$

where :

$Y_{i j k}$ is the number of years of life saved for a given age/race/ethnicity $i j$ in state $k$, $D_{i j k}$ is the number of COVID deaths for a given age/race/ethnicity $i j$ in state $k$, $S L E_{i}$ is the standard life expectancy at age $i$ in the USA in 2019 . We extend the equations 4, 5, and 6 above to compute $Y S_{j k}$ and $Y F_{j k}$, the number of years of lives saved under both policies $S$ and $F$ by including the $S L E_{i}$ term. We thus obtain: 


$$
Y S_{j k}=v * \frac{D_{65-74 j k}}{N_{65-74 k}} * S L E_{65-74}
$$

and,

$$
\begin{gathered}
Y F_{i j k}=v * R * \frac{D_{i j k}}{N_{i j k}} * \frac{N_{i j k}^{F}}{N_{k}^{F}} * S L E_{i} \\
Y F_{j k}=\sum Y F_{i j k}
\end{gathered}
$$

Then, similarly as in equation 7 , we compute a new ratio ratio $_{j k}$, showing the relative performance of policies $S$ and $F$ in terms of number of lives saved:

$$
\operatorname{ratio} Y_{j k}=\frac{Y S_{j k}}{Y F_{j k}}
$$

\section{Results}

\subsection{Comparative vaccine dose allocation and mortality rates by race / ethnicity}

Table 2 shows that Non-Hispanic Whites receive more doses under policy $S$ than under policy $F$, while all other groups (Hispanics, Non-Hispanic Blacks and Non-Hispanic Asians, Non-Hispanic Two or more races, Non-Hispanic American Indian or Alaska Native, and NonHispanic Native Hawaiian or other Pacific Islander) receive more doses under policy $F$. This can be explained by the over-representation of Non-Hispanic Whites among elderly in the US (Supplementary Figure 1).

Next we show the estimated COVID-19 mortality rates per 100,000 individuals, per race/ethnicity, for individuals aged 65 to 74 and for front-line workers. As shown in bold in Table 2, for all races the mortality rates are considerably higher among older individuals compared to essential workers. Also, Hispanics, Non-Hispanic Blacks, Non-Hispanic American Indian or Alaska Native and Non-Hispanic Native Hawaiian or other Pacific Islander 65-74 have higher mortality rates than Non-Hispanic Whites and Asians. The calculations in Table 2 are repeated for each state and the District of Columbia in Supplementary Table 3. 
medRxiv preprint doi: https://doi.org/10.1101/2022.02.03.22270414; this version posted February 4, 2022. The copyright holder for this preprint (which was not certified by peer review) is the author/funder, who has granted medRxiv a license to display the preprint in perpetuity.

It is made available under a CC-BY-NC-ND 4.0 International license .

Table 2: Proportion of doses allocated under policy $S$ and policy $F$, and mortality rates per 100,000 individuals for individuals 65-74 year olds and for front-line workers, per race/ethnicity categories in the United States. For each race/ethnicity category the highest proportion of doses and mortality rate are in bold.

"2+ races" stands for Two or more races, "Native" stands for American Indian or Alaska Native, and "NHPI" stands for Native Hawaiian or other Pacific Islander.

\begin{tabular}{|c|c|c|c|c|}
\hline \multirow[b]{2}{*}{ Race/ethnicity } & \multicolumn{2}{|c|}{ Proportion of doses } & \multicolumn{2}{|c|}{ Mortality rate } \\
\hline & $\begin{array}{c}\text { received } \\
\text { under } \\
\text { policy } S\end{array}$ & $\begin{array}{l}\text { received } \\
\text { under } \\
\text { policy F }\end{array}$ & $\begin{array}{c}\text { among } \\
\text { 65-74 year } \\
\text { olds }\end{array}$ & $\begin{array}{c}\text { among } \\
\text { front-line } \\
\text { workers }\end{array}$ \\
\hline All races & 100 & 100 & $39 \cdot 5$ & $6 \cdot 9$ \\
\hline Non-Hispanic White & $74 \cdot 6$ & $58 \cdot 2$ & $27 \cdot 1$ & $3 \cdot 7$ \\
\hline Hispanic & $9 \cdot 0$ & $19 \cdot 7$ & $95 \cdot 2$ & $12 \cdot 6$ \\
\hline Non-Hispanic Black & $10 \cdot 0$ & $13 \cdot 2$ & $82 \cdot 4$ & $12 \cdot 2$ \\
\hline Non-Hispanic Asian & $4 \cdot 7$ & $5 \cdot 4$ & $33 \cdot 2$ & $5 \cdot 9$ \\
\hline Non-Hispanic $2+$ races & 0.9 & $2 \cdot 6$ & $17 \cdot 3$ & $2 \cdot 3$ \\
\hline Non-Hispanic Native & $0 \cdot 5$ & 0.7 & $105 \cdot 0$ & $27 \cdot 5$ \\
\hline Non-Hispanic NHPI & $0 \cdot 1$ & 0.2 & $96 \cdot 1$ & $36 \cdot 7$ \\
\hline
\end{tabular}

\subsection{Comparative number of lives saved under policies $S$ and $F$ by race/ethnicity}

Next, we compute the number of lives saved in each race/ethnicity group by vaccinating 1,000 individuals, targeting either individuals aged 65-74 (policy $S$ ), or front-line workers (policy $F$ ). As shown in Table 3, for the total US population as well as each race/ethnicity groups, the number of lives saved is higher when vaccinating 65-74 year olds $\left(L S_{j}\right)$ compared to vaccinating front-line workers $\left(L F_{j}\right)$. The ratio $\frac{L S_{j}}{L F_{j}}$ indicates for each race/ethnicity group how much better policy $S$ performs when compared to policy $F$. Policy $S$ is expected to save more lives for each race/ethnicity individually, and overall. However, the comparative performance of policy $S$ is most beneficial for Non-Hispanic Whites than for any other race/ethnicity category.

The calculations in Table 3 are repeated for each state and the District of Columbia for which the number of deaths reported among both 16-64 and 65-74 year olds was larger or equal to 10, as shown in Figure 1 and Supplementary Table 4. In all of race and state combinations for which ratios could be computed, ratios are larger than 1, suggesting that policy $S$ performs best across geographies. Again, Non-Hispanic Whites benefited most from policy $S$. 
Table 3: Number of lives saved in each race/ethnicity group by vaccinating 1,000 individuals, either allocating doses to individuals 65-74 $\left(L S_{j}\right)$ or to front-line workers $\left(L F_{j}\right)$. The ratio $\frac{L S_{j}}{L F_{j}}$ shows the relative number of lives saved comparing the two policies. Results shown per race/ethnicity categories for the United States. "2+ races" stands for Two or more races, "Native" stands for American Indian or Alaska Native, and "NHPI" stands for Native Hawaiian or other Pacific Islander.

\begin{tabular}{l|c|c|c}
\hline \multicolumn{1}{c|}{ Race/ethnicity } & $L S_{j}$ & $L F_{j}$ & Ratio \\
\hline All races & 0.375 & 0.066 & $\mathbf{5 . 7}$ \\
\hline Non-Hispanic White & 0.192 & 0.021 & $\mathbf{9 . 4}$ \\
\hline Hispanic & 0.082 & 0.024 & $\mathbf{3 . 5}$ \\
\hline Non-Hispanic Black & 0.078 & 0.015 & $\mathbf{5 . 1}$ \\
\hline Non-Hispanic Asian & 0.015 & 0.003 & $\mathbf{4 . 9}$ \\
\hline Non-Hispanic 2+ races & 0.002 & 0.001 & $\mathbf{2 . 7}$ \\
\hline Non-Hispanic Native & 0.005 & 0.002 & $\mathbf{3 . 0}$ \\
\hline Non-Hispanic NHPI & 0.0010 & 0.0007 & $\mathbf{1 . 5}$ \\
\hline
\end{tabular}


medRxiv preprint doi: https://doi.org/10.1101/2022.02.03.22270414; this version posted February 4, 2022. The copyright holder for this preprint (which was not certified by peer review) is the author/funder, who has granted medRxiv a license to display the preprint in perpetuity.

It is made available under a CC-BY-NC-ND 4.0 International license .

Figure 1: Comparative performance of policies $S$ and $F$ (shown in the form of a ratio - ) for all race/ethnicity categories in all states and the District of Columbia in terms of lives saved. States are grouped by HHS Region.

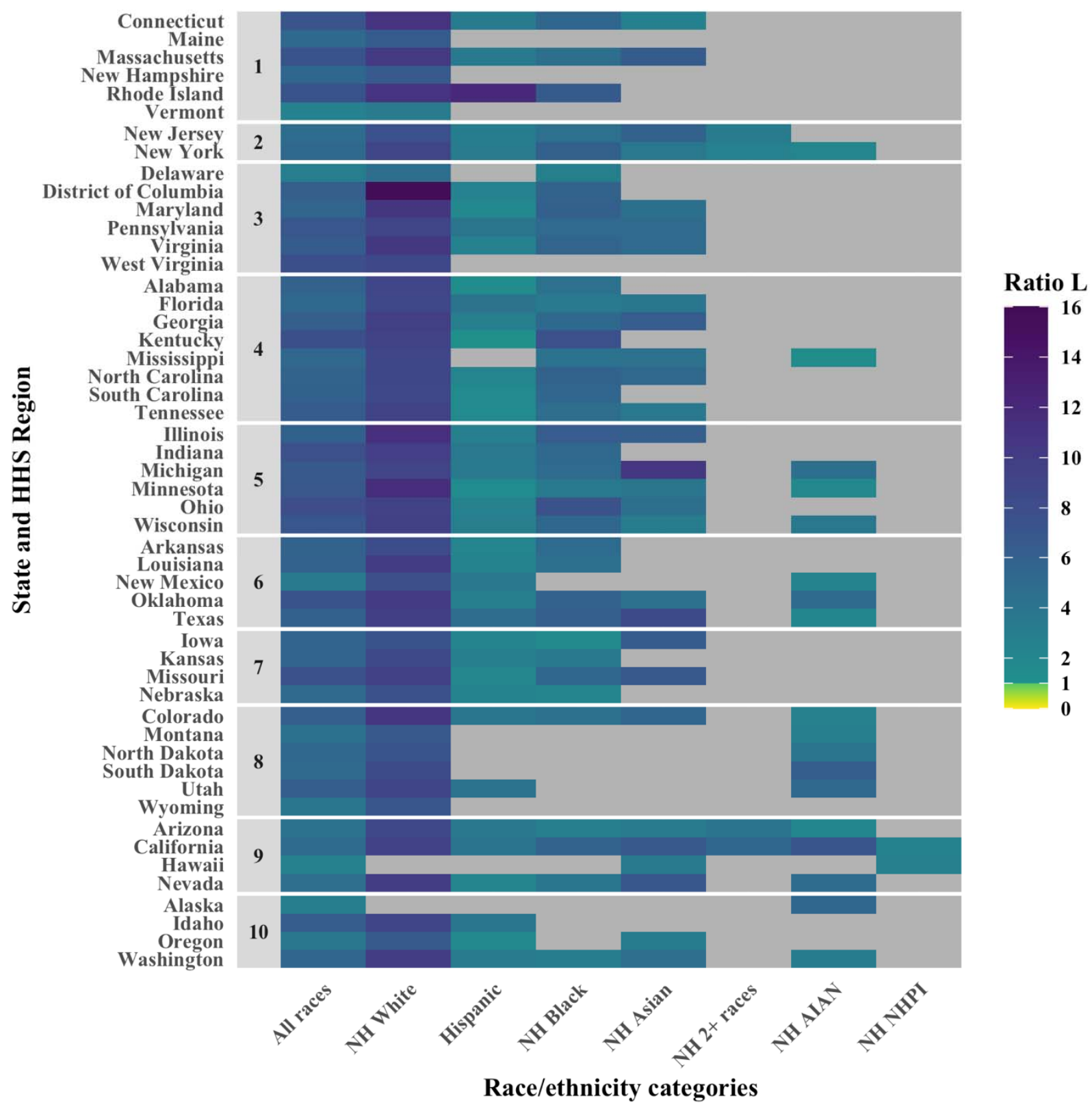


medRxiv preprint doi: https://doi.org/10.1101/2022.02.03.22270414; this version posted February 4, 2022. The copyright holder for this preprint (which was not certified by peer review) is the author/funder, who has granted medRxiv a license to display the preprint in perpetuity.

It is made available under a CC-BY-NC-ND 4.0 International license .

\subsection{Comparative number of years of life saved under policies $S$ and $F$ by race/ethnicity}

Next, we compute the number of years of life saved in each race/ethnicity group by vaccinating 1,000 individuals, targeting either individuals aged 65-74 (policy $S$ ), or frontline workers (policy $F$ ).

As shown in Table4, for the whole US populations, as well as for most racial/ethnicity groups, more years of life are saved under policy $S$ than policy $F$. Only Non-Hispanic Native Hawaiian and other Pacific Islanders would benefit more from a vaccination strategy targeting front-line workers. Similarly to Table 3, Non-Hispanic Whites would benefit most from a vaccination priorizing older 65-74 individuals.

The ratio $_{j k}$ ratios shown in Table 4 are closer to 1 than the ratio $L_{j k}$ shown in Table 3 , indicating that accounting for number of years of life lost leads to more similar performance for both policies.

The calculations in Table 4 are repeated for each state and the District of Columbia for which the number of deaths reported among both 16-64 and 65-74 year olds was larger or equal to 10, as shown in Figure 2 and Supplementary Table 5. In the vast majority of race and state combinations for which ratios could be computed, ratios are larger than 1 , suggesting that policy $S$ performs best across geographies. Fourteen race/ethnicity/state combinations lead to ratios smaller than 1 , indicative of a better performance of policy $F$, as shown in orange colours in Figure 2.

Table 4: Number of years of life saved in each race/ethnicity group by vaccinating 1,000 individuals, either allocating doses to individuals 65-74 $\left(Y S_{j}\right)$ or to front-line workers $\left(Y F_{j}\right)$. The ratio $\frac{Y S_{j}}{Y F_{j}}$ shows the relative number of lives saved comparing the two policies. Results shown per race/ethnicity categories for the United States. "2+ races" stands for Two or more races, "Native" stands for American Indian or Alaska Native, and "NHPI" stands for Native Hawaiian or other Pacific Islander.

\begin{tabular}{l|c|c|c}
\hline \multicolumn{1}{c|}{ Race/ethnicity } & $Y S_{j}$ & $Y F_{j}$ & Ratio \\
\hline \hline All races & 6.53 & 2.08 & $\mathbf{3 . 1 4}$ \\
\hline Non-Hispanic White & 3.35 & 0.62 & $\mathbf{5 . 4 4}$ \\
\hline Hispanic & 1.43 & 0.77 & $\mathbf{1 . 8 6}$ \\
\hline Non-Hispanic Black & 1.36 & 0.49 & $\mathbf{2 . 7 7}$ \\
\hline Non-Hispanic Asian & 0.26 & 0.09 & $\mathbf{2 . 7 8}$ \\
\hline Non-Hispanic 2+ races & 0.03 & 0.02 & $\mathbf{1 . 2 7}$ \\
\hline Non-Hispanic Native & 0.10 & 0.07 & $\mathbf{1 . 4 5}$ \\
\hline Non-Hispanic NHPI & 0.02 & 0.02 & $\mathbf{0 . 7 2}$ \\
\hline \hline
\end{tabular}


medRxiv preprint doi: https://doi.org/10.1101/2022.02.03.22270414; this version posted February 4, 2022. The copyright holder for this preprint (which was not certified by peer review) is the author/funder, who has granted medRxiv a license to display the preprint in perpetuity.

It is made available under a CC-BY-NC-ND 4.0 International license .

Figure 2: Comparative performance of policies $S$ and $F$ (shown in the form of a ratio - ) for all race/ethnicity categories in all states and the District of Columbia in terms of years of life saved. States are grouped by HHS Region.

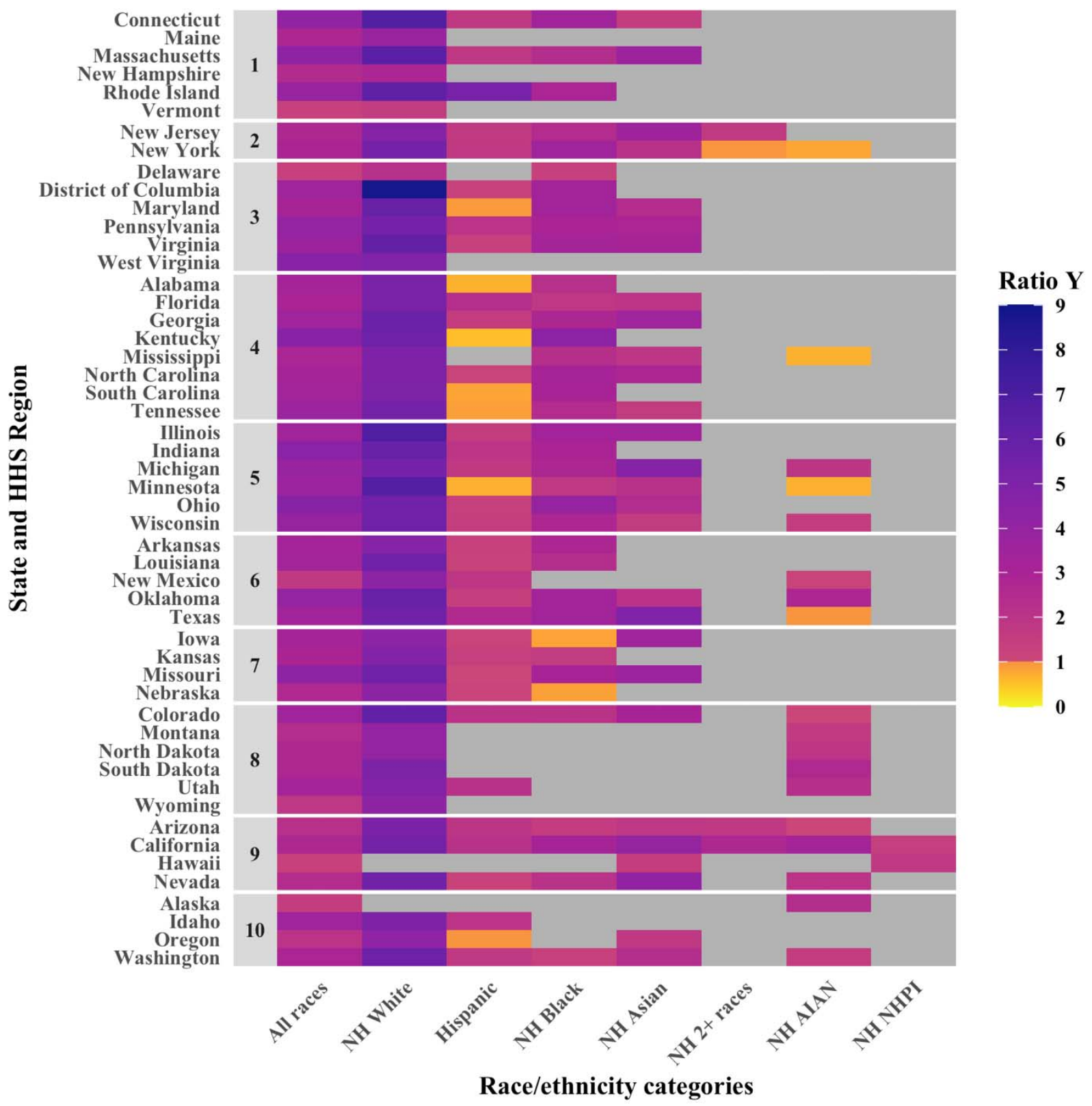


medRxiv preprint doi: https://doi.org/10.1101/2022.02.03.22270414; this version posted February 4, 2022. The copyright holder for this preprint (which was not certified by peer review) is the author/funder, who has granted medRxiv a license to display the preprint in perpetuity.

It is made available under a CC-BY-NC-ND 4.0 International license .

\section{Discussion}

The burden of COVID-19 infections and deaths has been unequally distributed among racial and ethnic groups in the US, while deaths have been sharply higher among older age groups. The ethical imperatives of saving the most lives and attending to equity have led to debate about age- and occupation-based criteria for prioritizing access to vaccines when they are scarce $20-22$. Because the hardest-hit racial and ethnic groups in the US also have younger age distributions, prioritization schemes that favor older ages intrinsically provide fewer vaccines to members of these disadvantaged groups, as we quantify in Table 2 . This consideration has led some to suggest that equity goals could be better achieved by prioritizing vaccines for front-line workers, a category that has greater exposure to infection, has high pandemic-related excess mortality ${ }^{23}$, and that disproportionately includes members of highly-affected racial and ethnic groups.

One might expect that a policy such as prioritizing front-line workers, which provides more vaccine doses to Black, Hispanic, and Asian persons than prioritizing 65-74 year olds, would also save more lives in these non-White groups. On the other hand, some have argued that this is unlikely because for each race/ethnicity, risk of death increases dramatically with age, and providing more doses to relatively young members of the hardest-hit groups ahead of (a smaller number of) older members of these groups misses the opportunity to prevent deaths in these groups. Consistent with this latter argument, we have shown that in the United States as a whole and in nearly every state, a front-line worker prioritization saves fewer lives in each racial/ethnic group than prioritization of 65-74-year-olds, at least when considering the direct effects of vaccination in protecting the vaccinated person. Specifically, prioritizing 65-74 year olds is projected to save $3 \cdot 5$ times as many Hispanic lives, $5 \cdot 1$ times as many non-Hispanic Black, $4 \cdot 9$ times as many non-Hispanic Asian lives, 3.0 times as many Non-Hispanic American Indian and Alaska Native lives, 1.5 times as many Non-Hispanic Native Hawaiian or other Pacific Islander, 2.7 times as many nonHispanic multiracial lives, and 9.4 times more non-Hispanic White lives than prioritizing front-line workers. Simply put, this is because the dramatically higher COVID-19 mortality rates in older persons (ranging from 2.6 to $7 \cdot 5$ fold by our estimates for the different race/ethnicity groups) outweigh the more modest differences in representation of these groups among different races (ranging from 1-1-fold for Asians to 2-8-fold for individuals with two or more races). This is likely driven by the over-representation of younger adults among the front-line workers when compared to the general population (Supplementary Figure 2). In short, Blacks, Hispanics, Asians, American Indians and Alaska Natives, Native Hawaiian and other Pacific Islanders and individuals with more than one race get somewhat more vaccines under a front-line worker priority, but those vaccines go to individuals at much lower risk of dying.

This finding demonstrates by example that it is possible to choose a vaccine distribution strategy that provides greater equity in vaccine distribution by race/ethnicity, yet prevents fewer deaths in every racial/ethnic group. Under our assumptions, if one considers vaccines as means to the ends of saving lives, the greater number of lives saved under the age-based policy, including in the hardest-hit groups, should lead one to favor the age-based policy over the front-line-worker policy regardless of how one weighs overall societal benefit and benefit to the hardest-hit groups, because the age-based policy maximizes both. 
medRxiv preprint doi: https://doi.org/10.1101/2022.02.03.22270414; this version posted February 4, 2022. The copyright holder for this preprint (which was not certified by peer review) is the author/funder, who has granted medRxiv a license to display the preprint in perpetuity. It is made available under a CC-BY-NC-ND 4.0 International license .

Our model relies on multiple simplifying assumptions. We assume that (i) the vaccine efficacy and uptake is constant across age, race and location, (ii) the proportion of deaths that took place in nursing homes and long-term care facilities is constant across races for a given age and state (an assumption made because nursing home status of deaths is given by age and state, but not race), (iii) $10 \%$ of deaths recorded for the 15-24 year old category took place among 15 year olds, (iv) that we can account for the increased risk of infection and deaths among front-line workers by multiplying the mortality rate by an increased risk $R$ constant across age, race and state, and that (v) analyses by Mutambudzi et al. ${ }^{13}$ appropriately estimate this $R$.

Our analysis is subject to other limitations. First, we focus our analysis on one outcome: deaths. We did not assess the impact of the two vaccination policies on other outcomes such as number of infections, morbidity such as 'long COVID', hospitalization or other economic consequences. As it has been show that vaccination strategies targeting younger adults can lead to lower number of infections but higher number of deaths ${ }^{9}$, it is possible that vaccinating front-line workers would lead to less infections. Second, we assume that the number of deaths occurring after vaccine allocation and roll-out is proportional to the death count up to January 30, 2021 (more exactly is it assumed to be equal to $20 \%$ of the cumulative deaths up to that date in each age, race and state combination). We thus assume that the inequalities in infection and mortality rates stay constant over the duration of the pandemic. Third, we only consider the direct effect of vaccination on the vaccinated, and not the indirect effect of vaccination protecting the rest of the population by limiting onward transmission. When this work began, it was unclear how to what extent COVID-19 vaccines reduce transmission ${ }^{24}$. While evidence is now accumulating for substantial vaccine effects on infection and onward spread ${ }^{25}$, these results reflect the knowledge available at the time prioritization decisions were being made. Moreover, as the B.1.617.2 (Delta) and B.1.1.529 (Omicron) variants have become dominant worldwide, doubts on vaccine efficacy against it are being raised ${ }^{26}$. If the protection against transmission of Delta, Omicron, and future variants is indeed found to be limited, vaccine allocation strategies should focus on direct protection from infection. The magnitude of the relative benefit of the 65-74 strategy over the front-line strategy via direct protection studied here suggests that the greater indirect effects of vaccinating front-line workers would have to be large to make it superior in preventing deaths in any racial/ethnic group, or overall. Front-line workers and members of racial/ethnic minorities ${ }^{27}$ may be more likely to live in multi-generation households and contribute to more onward transmission than 65-74 year old individuals. Mulberry et al. ${ }^{28}$ studied the indirect effect of vaccination (without considering race/ ethnicity) using an agestratified SEIR model including compartment for essential workers. Under strong assumptions that drastic social distancing measured are in place (no workplace contacts for non-essential workers and all contacts reduced), that the impact of vaccination of transmission is strong, and that $R_{t}$ is not kept at very low levels, they showed that vaccinating essential workers and/or all adults 20-79 after individuals over 80 leads to lower number of infections, hospitalization and deaths than a solely age-based strategy. Further work is needed to understand these tradeoffs and the extent to which accounting for indirect protection might reverse our findings under the rapidly changing conditions of COVID-19. 
medRxiv preprint doi: https://doi.org/10.1101/2022.02.03.22270414; this version posted February 4, 2022. The copyright holder for this preprint (which was not certified by peer review) is the author/funder, who has granted medRxiv a license to display the preprint in perpetuity. It is made available under a CC-BY-NC-ND 4.0 International license .

Notwithstanding these limitations, we have shown that from the perspective of infections directly prevented, a front-line-worker COVID-19 vaccine prioritization strategy does not save as many lives as prioritization of 65-74 year olds, overall or in each racial/ethnic group, and that this effect is qualitatively consistent across US states.

Although these two strategies received the most attention from committees considering prioritization schemes, there may be other strategies that might outperform either one, as some work has already suggested. For example, once health-care workers and individuals aged 65+ are vaccinated, prioritizing adults at increased risk of severe COVID-19 would increase access to vaccines for Non-Hispanic Blacks, while Hispanics would receive most doses under a strategy targeting essential workers and Non-Hispanic Whites and Asians under a solely age-based strategy ${ }^{29}$. For the goal of saving the most lives with a prevention intervention such as vaccination, it is optimal to prioritize individuals in order of their estimated mortality risk from the disease, which is the product of the mortality risk if infected (the infection-fatality risk) and their probability of becoming infected (a function of exposure). It is evident in the United States and elsewhere, at least from the pandemic history to date, that both older age and non-White race or Hispanic ethnicity are associated with higher risks ${ }^{30}$. Mortality risk at a given age varies with racial/ethnic classification, as for instance, in the US in 2020 Non-Hispanic American Indian or Alaskan Native aged 35-44 and Hispanic individuals aged 45-54 had higher mortality rates than Non-Hispanic White individuals aged 55-64 (Supplementary Figure 3). It follows that a policy that allocated vaccine priority according to this criterion would at each age prioritize Black and Hispanic individuals over White ones, and would assign equal priority, all other factors being equal, to a younger Hispanic or Black individual as to an older White one ${ }^{31}$. A version of this approach - lower age cutoffs for Black persons to receive priority - has been proposed ${ }^{32}$ and would both enhance equity and, if done appropriately, also enhance the number of lives saved overall and for Black Americans compared to an age-only prioritization. Likewise, geographic targeting to areas of high risk would increase racial equity while improving access to vaccination for those at greater risk of death from COVID-19 31.

\section{Acknowledgement}

The authors thank Dr. Elizabeth Wrigley-Field and Dr. Ayesha Mahmud for useful comments on an earlier version of this work.

\section{References}

1. Levin AT, Hanage WP, Owusu-Boaitey N, Cochran KB, Walsh SP, Meyerowitz-Katz G. Assessing the age specificity of infection fatality rates for COVID-19: systematic review, meta-analysis, and public policy implications. Eur J Epidemiol. 2020 Dec;35(12):1123-38.

2. O’Driscoll M, Ribeiro Dos Santos G, Wang L, Cummings DAT, Azman AS, Paireau J, et al. Age-specific mortality and immunity patterns of SARS-CoV-2. Nature. 2021 Feb 4;590(7844):140-5. 
medRxiv preprint doi: https://doi.org/10.1101/2022.02.03.22270414; this version posted February 4, 2022. The copyright holder for this preprint (which was not certified by peer review) is the author/funder, who has granted medRxiv a license to display the preprint in perpetuity. It is made available under a CC-BY-NC-ND 4.0 International license .

3. Mackey K, Ayers CK, Kondo KK, Saha S, Advani SM, Young S, et al. Racial and Ethnic Disparities in COVID-19-Related Infections, Hospitalizations, and Deaths. Ann Intern Med. 2020 Dec 1;174(3):362-73.

4. Williamson EJ, Walker AJ, Bhaskaran K, Bacon S, Bates C, Morton CE, et al. Factors associated with COVID-19-related death using OpenSAFELY. Nature. 2020 Aug 20;584(7821):430-6.

5. Lassale C, Gaye B, Hamer M, Gale CR, Batty GD. Ethnic disparities in hospitalisation for COVID-19 in England: The role of socioeconomic factors, mental health, and inflammatory and pro-inflammatory factors in a community-based cohort study. Brain, Behavior, and Immunity. 2020 Aug;88:44-9.

6. Baqui P, Bica I, Marra V, Ercole A, van der Schaar M. Ethnic and regional variations in hospital mortality from COVID-19 in Brazil: a cross-sectional observational study. The Lancet Global Health. 2020 Aug;8(8):e1018-26.

7. National Institute for Communicable Diseases. COVID-19 Hospital Surveillance Update, South Africa [Internet]. 2021 Mar. Available from: https://www.nicd.ac.za/wpcontent/uploads/2021/03/NICD-COVID-19-Weekly-Sentinel-Hospital-Surveillnaceupdate-Week-10-2021.pdf

8. APM Research Lab Staff. The Color of Coronavirus: COVID-19 deaths analyzed by race and ethnicity in the US [Internet]. APM Research Lab. [cited 2021 Apr 12]. Available from: https://www.apmresearchlab.org/covid/deaths-by-race

9. Bubar KM, Reinholt K, Kissler SM, Lipsitch M, Cobey S, Grad YH, et al. Modelinformed COVID-19 vaccine prioritization strategies by age and serostatus. Science. 2021 Feb 26;371(6532):916-21.

10. Matrajt L, Eaton J, Leung T, Brown ER. Vaccine optimization for COVID-19: Who to vaccinate first? Sci Adv. 2020 Feb;7(6):eabf1374.

11. Moore S, Hill EM, Dyson L, Tildesley MJ, Keeling MJ. Modelling optimal vaccination strategy for SARS-CoV-2 in the UK. Perkins A, editor. PLoS Comput Biol. 2021 May 6;17(5):e1008849.

12. Hogan A, Winskill P, Watson 0, Walker P, Whittaker C, Baguelin M, et al. Report 33: Modelling the allocation and impact of a COVID-19 vaccine [Internet]. Imperial College London; 2020 Sep [cited 2020 Nov 26]. Available from: http://spiral.imperial.ac.uk/handle/10044/1/82822

13. Mutambudzi M, Niedwiedz C, Macdonald EB, Leyland A, Mair F, Anderson J, et al. Occupation and risk of severe COVID-19: prospective cohort study of 120075 UK Biobank participants. Occup Environ Med. 2020 Dec 9;oemed-2020-106731.

14. National Center for Health Statistics. Deaths involving coronavirus disease 2019 (COVID-19) by race and Hispanic origin group and age, by state [Internet]. [cited $2021 \mathrm{Apr}$ 
medRxiv preprint doi: https://doi.org/10.1101/2022.02.03.22270414; this version posted February 4, 2022. The copyright holder for this preprint (which was not certified by peer review) is the author/funder, who has granted medRxiv a license to display the preprint in perpetuity.

It is made available under a CC-BY-NC-ND 4.0 International license .

12]. Available from: https://data.cdc.gov/NCHS/Deaths-involving-coronavirus-disease2019-COVID-19/ks3g-spdg

15. National Center for Health Statistics. NVSS Provisional COVID-19 Deaths by Place of Death and Age [Internet]. [cited 2021 Apr 12]. Available from:

https://data.cdc.gov/NCHS/NVSS-Provisional-COVID-19-Deaths-by-Place-of-Death/4va6ph5s

16. United States Census Bureau. American Community Survey Data [Internet]. The United States Census Bureau. [cited 2021 Apr 12]. Available from:

https://www.census.gov/programs-surveys/acs/data.html

17. Commonwealth of Massachusetts. Massachusetts' COVID-19 vaccination phases [Internet]. [cited 2021 Apr 12]. Available from: https://www.mass.gov/infodetails/massachusetts-covid-19-vaccination-phases

18. WHO Global Health Observatory. Life tables by country - United States of America [Internet]. WHO. World Health Organization; [cited 2021 May 20]. Available from: https://apps.who.int/gho/data/view.main.61780?lang=en

19. Martinez R, Soliz P, Caixeta R, Ordunez P. Reflection on modern methods: years of life lost due to premature mortality-a versatile and comprehensive measure for monitoring non-communicable disease mortality. International Journal of Epidemiology. 2019 Aug 1;48(4):1367-76.

20. Persad G, Peek ME, Emanuel EJ. Fairly Prioritizing Groups for Access to COVID-19 Vaccines. JAMA. 2020 0ct 27;324(16):1601.

21. Schmidt H, Gostin LO, Williams MA. Is It Lawful and Ethical to Prioritize Racial Minorities for COVID-19 Vaccines? JAMA. 2020 Nov 24;324(20):2023.

22. Committee on Equitable Allocation of Vaccine for the Novel Coronavirus, Board on Health Sciences Policy, Board on Population Health and Public Health Practice, Health and Medicine Division, National Academies of Sciences, Engineering, and Medicine. Framework for Equitable Allocation of COVID-19 Vaccine [Internet]. Gayle H, Foege W, Brown L, Kahn B, editors. Washington, D.C.: National Academies Press; 2020 [cited 2021 Apr 28]. Available from: https://www.nap.edu/catalog/25917

23. Chen Y-H, Glymour M, Riley A, Balmes J, Duchowny K, Harrison R, et al. Excess mortality associated with the COVID-19 pandemic among Californians 18-65 years of age, by occupational sector and occupation: March through November 2020. Devleesschauwer B, editor. PLoS ONE. 2021 Jun 4;16(6):e0252454.

24. Lipsitch M, Dean NE. Understanding COVID-19 vaccine efficacy. Science. 2020 Nov 13;370(6518):763-5.

25. Shah ASV, Gribben C, Bishop J, Hanlon P, Caldwell D, Wood R, et al. Effect of vaccination on transmission of COVID-19: an observational study in healthcare workers and 
medRxiv preprint doi: https://doi.org/10.1101/2022.02.03.22270414; this version posted February 4, 2022. The copyright holder for this preprint (which was not certified by peer review) is the author/funder, who has granted medRxiv a license to display the preprint in perpetuity. It is made available under a CC-BY-NC-ND 4.0 International license .

their households [Internet]. Public and Global Health; 2021 Mar [cited 2021 Apr 28]. Available from: http://medrxiv.org/lookup/doi/10.1101/2021.03.11.21253275

26. Chia PY, Xiang Ong SW, Chiew CJ, Ang LW, Chavatte J-M, Mak T-M, et al. Virological and serological kinetics of SARS-CoV-2 Delta variant vaccine-breakthrough infections: a multi-center cohort study [Internet]. Infectious Diseases (except HIV/AIDS); 2021 Jul [cited 2021 0ct 6]. Available from:

http://medrxiv.org/lookup/doi/10.1101/2021.07.28.21261295

27. Cohn D, Passel JS. Record 64 million Americans live in multigenerational households [Internet]. Pew Research Center. 2018 [cited 2021 Sep 22]. Available from:

https://www.pewresearch.org/fact-tank/2018/04/05/a-record-64-million-americanslive-in-multigenerational-households/

28. Mulberry N, Tupper P, Kirwin E, McCabe C, Colijn C. Vaccine Rollout Strategies: The Case for Vaccinating Essential Workers Early [Internet]. Infectious Diseases (except HIV/AIDS); 2021 Feb [cited 2021 Apr 12]. Available from: http://medrxiv.org/lookup/doi/10.1101/2021.02.23.21252309

29. Selden TM, Berdahl TA, Fang Z. Research Findings \#46: COVID-19 Vaccination Prioritization Scenarios and Their Effects on Eligibility by Poverty Level, Race, and Ethnicity [Internet]. Agency for Healthcare Research and Quality; 2021 Mar. Available from: https://meps.ahrq.gov/data_files/publications/rf46/rf46.shtml

30. Bassett MT, Chen JT, Krieger N. Variation in racial/ethnic disparities in COVID-19 mortality by age in the United States: A cross-sectional study. Tsai AC, editor. PLoS Med. 2020 Oct 20;17(10):e1003402.

31. Wrigley-Field E, Kiang MV, Riley AR, Barbieri M, Chen Y-H, Duchowny KA, et al. Geographically-targeted COVID-19 vaccination is more equitable than age-based thresholds alone [Internet]. Epidemiology; 2021 Mar [cited 2021 Apr 12]. Available from: http://medrxiv.org/lookup/doi/10.1101/2021.03.25.21254272

32. Blackstock 0, Blackstock U. Opinion?: Black Americans should face lower age cutoffs to qualify for a vaccine. Washington Post [Internet]. 2021 Feb 19 [cited 2021 Apr 12]; Available from: https://www.washingtonpost.com/opinions/black-americans-should-facelower-age-cutoffs-to-qualify-for-a-vaccine/2021/02/19/3029d5de-72ec-11eb-b8a9b9467510f0fe_story.html 